"This is the pre-peer reviewed version of the following article Schedlitzki, D., Ahonen, P., Edwards, G.P., Gaggiotti, H., and Wankhade, P. (forthcoming). Leadership and Language: a research agenda.

International Journal of Management Review, which has been published in final form at http://onlinelibrary.wiley.com/doi/10.1111/ijmr.12100/abstract This article may be used for noncommercial purposes in accordance with Wiley Terms and Conditions for Self-Archiving."

\title{
Working with language: a refocused research agenda for cultural leadership studies
}

\section{Abstract}

This article critically reviews existing contributions from the field of cultural leadership studies with a view to highlighting the conceptual and methodological limitations of the dominant etic, cross-cultural approach in leadership studies and illuminating implications of the relative dominance and unreflective use of the English language as the academic and business lingua franca within this field. It subsequently outlines the negative implications of overlooking cultural and linguistic multiplicity for our understanding of culturally sensitive leadership practices. In drawing on lessons from this critical review and the emergent fields of emic, non-positivist cultural leadership studies, this analysis argues that the field of cultural leadership studies requires an alternative research agenda focussed on language multiplicity that enables the field to move towards emic, qualitative research that helps to empower individual cultural voices and explore cultural intra- and interrelationships, tensions and paradoxes embedded in leadership processes. The article concludes by offering suggestions on methodological approaches for emic cultural leadership studies that are centred on the exploration of language as a cultural voice.

Key words: Leadership, Culture, Language, Multiplicity, Methodology 


\section{Considering the importance of language multiplicity for cultural leadership studies}

The field of leadership research has undergone significant changes over the last two decades. Traditionally approached from a psychological perspective (see Clifton 2015), the field has seen a rise in studies taking relational and constructionist approaches to leadership (e.g. Hosking and Morley 1988; Grint 2005; Fairhurst 2007; Ford et al., 2008; Cunliffe and Eriksen 2011; Uhl-Bien and Ospina 2012) and offering critical contributions focussed on gender, power relations, resistance and difference in leadership (e.g. Gordon 2002, 2011; Collinson 2005, 2006, 2014; Ford, 2006, 2010; Zoller and Fairhurst, 2007). Empirically, the field has seen a rise in the number and importance of qualitative research studies (Parry et al. 2014), particularly those taking a discursive or communicative approach (Fairhurst and Connaughton 2014; Tourish 2014) and those embracing aesthetic methods of enquiry (Edwards et al. 2015). This change in the research culture within leadership studies is promising to shed more detailed light on how leadership is co-created in practice and illuminate processes of communicative interaction and power dynamics (Fairhurst and Uhl-Bien 2012).

Yet, just as in the wider field of management studies (Steyaert and Janssens 2013), these changes have so far taken place within an assumed monolingual space, where English as the language of research and publication has been largely used without further reflection. Although language use, discourse and related power dynamics are the very focus of empirical research taking a social constructionist or critical perspective on leadership, these studies largely take place and get published exclusively in the English language without paying much attention to its nature, its peculiarities and specificities. As such, the field of leadership studies lacks critical reflection on the complex hegemonic role of the English language as a publication and business lingua franca (cf. Meriläinen et al. 2008). 
The majority of research in both mainstream psychological and emergent critical, social constructionist leadership studies has - in their own culturally informed empirical ways explored in depth the different meanings and constructions of leadership within the English language and at times questioned the very existence of leadership in certain organisational contexts (e.g. Sutherland et al. 2013). Yet, as a field it has not paused to consider the cultural and linguistic relevance of the very notion of leadership outside the English language (for exceptions, see Prince 2006; Koivunen 2007; Jepson 2010). Indeed, popular western based concepts such as 'transformational leadership' have been exported to non-English speaking countries (Diaz-Saenz 2011), with a host of empirical studies testing their applicability across the globe (e.g. Spreitzer et al. 2005; Schaubroeck et al. 2007; Jung et al. 2009). Yet such studies have failed to fundamentally question the cultural relevance of the very notion (Osborn and Marion 2009) and have instead assumed cross-cultural homogeneity of the phenomenon as well as unproblematic linguistic transferability.

This has particularly strong implications for the sub-field of cultural leadership studies (Jepson 2010), where the predominant focus on cross-cultural comparisons through the use of standardised questionnaires has further enhanced the overlooking of cultural and language multiplicity (Meriläinen et al. 2008; Steyaert and Janssens 2013). Zhang et al. (2012: 1063) argue that it is imperative for the advancement of cultural leadership studies to promote indigenous leadership research that centres on and uses 'local language, local subjects and local perspectives'. They show that the vast majority of cross-cultural (predominantly quantitative) leadership research has to date taken a fundamentally non-local approach to studying indigenous forms and configurations of leadership. Yet, in their proposal of a detailed framework for studying indigenous leadership, even Zhang et al. (2012) fall into the same essentialist approach 
to culture and language by failing to address multiplicity in both culture and language. In this article, we explore the negative repercussions of overlooking language multiplicity (both within and beyond the English and other languages) for cultural leadership studies and the opportunities that a research agenda focussed on cultural and language multiplicity offers by encouraging exploration of difference, power and dynamics in cultural leadership studies and practice.

The importance of uncovering power dynamics within (and beyond) the English language has been highlighted previously by Stephens (2003), who used interviews of women leaders to demonstrate the way that language shaped their sense of themselves as leaders. By doing so, she highlighted the particular way language and culture interact to promote dominant notions of leadership and hide others from view. Women's leadership, for example, has been hidden beneath traditional and largely gendered words for leadership such as 'king', 'master' and 'chairman' that refer exclusively to men. Women's traditional forms of leadership have been ignored or actively defined as being outside of what it might be to 'lead'. Related arguments on the gendered nature of leadership assumptions embedded in hegemonic leadership discourse have been put forward by other scholars (e.g. Ford 2006, 2010; Elliott and Stead 2008, 2009; Ford et al. 2008; Muhr and Sullivan 2013). This has helped to highlight the importance of paying attention to language multiplicity within the English language and particularly the way in which masculinised norms pervade academic and organisational leadership discourse and institutionalise gendered notions of leadership in organisational practice. Building on these constructionist and critical contributions on power dynamics in language-in-use, we seek to expand the debate into the importance of language beyond the English language, by highlighting wider implications of linguistic multiplicity for our understanding of culture and our conceptualisation of leadership. 
The aim of this article is then to critically review the field of cultural leadership studies. In our conceptualization of 'cultural leadership studies' we rely and build on the existing transdisciplinary field of Cultural Studies. The field itself can be divided along various lines (for example geographic) and into a number of schools with their particular areas of emphasis in terms of theoretical orientation or the object of study, or both. There are also a number of differing conceptualizations of culture, with meanings related to civilization, the ordinary and the everyday, resistance (of sub and countercultures) and identity (in terms of class, 'race', sexuality, or otherwise). With this plurality distinctly in mind, we define 'cultural leadership studies' as a field of interconnected, complementary as well as competing perspectives on both culture as well as leadership. Whatever the emphases, however, 'cultural leadership studies' are concerned with such aspects as social meanings given to leadership and ways of leading, practices that produce leadership, knowledges that constitute leadership and power relations that are integral to and intertwined with leadership. Our focus in this article is to provide a synopsis of and evaluate the different conceptual and methodological approaches to studying leadership and culture of the dominant stream of etic, cross-cultural leadership studies and the emergent field of emic, nonpositivist cultural leadership studies, which covers only a part or a subsection of the broad definition of cultural leadership studies. Taking this very specific approach will enable us to evaluate the need for an alternative research agenda that embraces multiplicity in cultures and explores these through the lens of multilingualism. We argue that this focus on leadership and language multiplicity for cultural leadership studies will enable us to move away from an overreliance on dichotomisation (Collinson 2014) and categorisations towards exploring cultural and linguistic intra and inter-relationships, tensions, power dynamics and paradoxes present in 
leadership practice. To this end, we provide suggestions on methodological approaches that centre on the exploration of language as a cultural voice.

\section{Review Approach}

Our critical review of the dominant stream of etic, cross-cultural leadership studies and the emergent field of emic, non-positivist cultural leadership studies seeks to provide a synopsis of dominant and emergent conceptual and methodological approaches to studying the relationship between leadership and culture. In particular, it seeks to gain an understanding of the current attention paid to language and the presence of different conceptualisations of culture within this body of literature. To adequately inform this synopsis, our literature searches focussed on conceptual articles and empirical studies of culture and leadership, including a follow-up search for contributions specifically focussed on language, culture and leadership. We outline below in detail our processes of searching and categorising this literature.

\section{Literature Search Process}

In light of the aforementioned broad definition of cultural leadership studies and the popularity of the phenomena of leadership and culture, we had to engage in several search and elimination processes to identify and gain an overview of relevant published output. It is important to note that we only searched for and considered contributions on leadership and culture within managerial contexts and as such excluded articles on political or religious leadership. We ran several searches within key databases such as Business Source Premier, 
Science Direct and Emerald as they were expected to cover most comprehensively relevant peer reviewed journals that are recognised for publishing articles on leadership and culture of relevance to this review. A general search within Business Source Premier for full texts from academic journals using the keywords leadership and culture brought up 1437 hits. By selecting a range of subjects indicative of cross-cultural, intercultural and multicultural work we narrowed the outputs down to 224 . We systematically went through all these 224 articles to identify those that were specifically focussed on leadership and indigenous, regional, national or global culture (including postcolonial studies) and discarded those that instead were focussed on organisational, corporate and professional culture or more broadly management rather than leadership. We further deselected those articles that explored the applicability of specific leadership theories (e.g. transformational, ethical leadership) in a specific country without explicitly considering the regional or national culture. Taking such a selective approach enabled us to focus on our core aim of analysing categories of conceptualisation and methodology used to examine the relationship between culture and leadership in existing studies. Finally, we restricted our reading of articles to those published within the last 20 years, i.e. after 1995 , leading to a total of 16 articles.

We also ran several specific searches within this database, using keywords such as quantitative research, qualitative research, cross-cultural and intercultural to look for themes on different methodological approaches. Similar searches were conducted and elimination criteria applied in Science Direct and Emerald, exploring specifically 3 and 23 journal articles respectively with a view to establishing categories of research approaches to the relationship between culture and leadership. 
Building on these database searches, we noticed that not all relevant journals had been covered, for example no publications from Leadership were captured. We therefore also scanned content lists for leadership specific journals such as The Leadership Quarterly, Leadership, Leadership and Organization Development Journal for relevant publications on leadership and regional/national culture from the last 10 years. This specific search helped us to find further non-positivist studies (including indigenous, linguistic and postcolonial studies). We also paid attention here to review articles and critical debates on the subject of leadership and culture. Upon completion of these searches, we supplemented our predominant focus on peer reviewed articles with relevant books and book chapters, resulting in a total of 82 sources.

To ensure that we had captured specific contributions on language in relation to culture and leadership and to gain an overview of the volume of such work, we reviewed both our newly created list of publications and scanned once more content lists of leadership specific journals. Searches within Business Source Premier, Science Direct and Emerald returned a very limited number of articles when using 'language' as a keyword in combination with 'leadership' and 'culture'. Indeed, when searching these databases for articles on leadership and language more generally, we found a strong focus on exploring language as a tool for motivation and persuasion, whereas only one article (Zander et al. 2011) explored language in relation to culture.

\section{Literature Categorisation}

Several themes emerged from the reviewed literature in relation to the underpinning assumptions of their conceptualisations of leadership and culture and their methodological approach. All 83 sources were therefore categorised according to: research approach (emic or 
etic); methods used (qualitative, quantitative, mixed); cross-cultural, intra-cultural or intercultural focus; focus on language. We also noted the presence of dominant research approaches and debates within leadership specific journals as well as the existence of critiques (e.g. Graen 2006; Jepson 2009; Guthey and Jackson 2011). In light of the very limited use and focus on language in cultural leadership studies to date, we decided to include review articles, books and book chapters focussed more generally on discursive, linguistic, communicative and aesthetic approaches to studying leadership and selected contributions from the wider management and the communications literature to enhance our critical review of methodological and conceptual approaches to studying culture and leadership.

The rest of this article will draw on this total of 143 sources to present the themes emerging from the above categorisation process. We first draw on insights from the communications and management literature to summarise differences in cultural research that were also discovered as two main themes in our categorisation process. This is followed by a critical evaluation of the dominant etic, cross-cultural approach in leadership studies and a discussion of the key contributions of the emergent field of emic, non-positivist cultural leadership studies to recognising the importance of cultural and linguistic multiplicity in cultural leadership studies. This then enables us to propose a revised research agenda and methodological approaches for cultural leadership studies focussed on language.

\section{Intra-cultural differences in cultural research}

Before delving into our review of the cultural leadership research landscape, we would like to draw on a long-standing debate in the communication and management literatures around the 
merits and limitations of different approaches to studying and conceptualising culture. This will help to highlight the differences in cultural research that were found to divide leadership studies into two fundamentally exclusive camps: those focussing on etic, cross-cultural comparisons, working from within the longstanding, dominant perspective of psychometric study and those taking an emic, non-positivist approach, representing an emergent counter-culture of sociological/critical study of leadership and culture.

\section{Conceptualising culture - two approaches}

Firstly, Holiday et al. (2004) illuminate different research approaches by focussing on the different nature of enquiry between essentialist views of culture (e.g. Hofstede 1980) and nonessentialist views of culture (e.g. Geertz 1973). They reflect on how different cultural approaches influence the way we talk about cultures and arguably behave towards individuals from different cultures. Czarniawska-Joerges (1992) and Gaggiotti et al. (2014) suggest that the difference between essentialist and non-essentialist views of culture could be the consequence of the academic separation of organization studies and anthropology that having come together in the Hawthorne Studies moved apart over time (after the 1930s). An essentialist view of culture is to see culture as an ontological entity with clearly defined membership boundaries where traits and characteristics are shared equally by all members, enabling the researcher to categorise individuals into identifiable 'cultures'. Research studies adopting this kind of essentialist approach to culture tend to divide the world into separate and mutually exclusive national cultures - often defining cultural boundaries as geographical 'country of origin' (Altman and Laguecir 2012) - and study at group level how people in one culture are different from people in another culture (Holiday et al. 2004). This allows for large-scale comparative studies to 
generalise their findings across entire cultural populations, thereby reifying difference and reinforcing separation. This essentialist approach to culture has received widespread criticism within the field of management studies (e.g. Tayeb 2001; McSweeney 2002; Ailon-Souday and Kunda 2003; Altman and Laguecir 2012) for conveying too static and minimalist a view of culture that exaggerates cultural uniformity within geographical boundaries and downplays cultural dynamics, overlaps and multiplicity as well as the historicity of culture.

In contrast, Holiday et al. (2004) define a non-essentialist approach to view culture as a social force that is complex with characteristics that are hard to define exclusively and may be relating to any type of group and discourse at any point in time. It acknowledges that cultures are multiple, fluid, changing and are hence not tied to fixed boundaries but these boundaries are rather blurred and shifting, where individuals may belong to and move between multiple different cultures both within and across societies. Individual behaviour is hence influenced by a multiplicity of cultures at different levels of intensity and these influences change over time. Recognising multiplicity in cultural membership and fluid boundaries of particular cultures is then further linked to becoming aware of multiplicity of languages of particular cultures languages that in many ways constitute and bring the cultures into being - and stressing the ‘interplay between voices and social languages' (Steyaert and Janssens 2013: 133).

\section{Studying Culture - two approaches}

Asante and Gudykunst (1989) draw our attention to the fundamental methodological differences between etic, cross-cultural and emic, intra- and inter-cultural research. Embodying an etic (culture-general) and essentialist approach, cross-cultural studies are fundamentally concerned with comparing cultures, thereby assuming homogeneity within a culture as well as 
discernible differences between cultures. This approach requires imposition of structure by the researcher and an assumption of universally applicable and absolute criteria of culture comparison. Often employing a standardised questionnaire based methodological approach that is created in one language and then translated into other languages, this approach treats language as an 'asocial conduit for the transmission of meanings' (Clifton 2015: 2). Ailon (2008) warns that standardisation in quantitative cross-cultural research ultimately leads to the silencing of other languages and intra-cultural meanings and to the favouring of one cultural regime of meanings (that of the researchers) over others. In addition, the practices of knowledge production, that is, the academic publication standards and procedures of management studies have arguably advantaged cross-cultural research from a Western, English-speaking perspective over those from countries that are less able to engage with this institutionalised and homogenised publication system (Meriläinen et al. 2008; Steyaert and Janssens 2013).

Emic approaches to cultural studies (Gudykunst and Nishida 1989), on the other hand, examine only one cultural setting in depth and aim to understand it from within the cultural system itself. Structure in emic studies is discovered by the researcher in situ and criteria relative to the internal characteristics found within the culture. To this end, studies are entirely focussed on and work within the local context, local language and seek to explore local perspectives and build locally meaningful conceptualisations of the phenomenon under study. As such, emic approaches to cultural studies are interested in variation within cultures and their relationships with other cultures, seeking to explore interrelationships, tensions and paradoxes in cultural and linguistic multiplicity. What they do not enable is comparison of cultures against 'universal' criteria, which in some scholarly settings is considered desirable and important. 


\section{Culture and leadership - a review of two research cultures}

In recognition of the merits and limitations of different cultural research approaches outlined above, we will focus our review of cultural leadership research to date on the different insights gained from a) the dominant strand of etic, cross-cultural leadership research and b) the emergent body of emic, non-positivist studies on culture and leadership. This will highlight the great diversity that exists within English speaking research into culture and leadership and build the foundation for our proposal of a revised research agenda for cultural leadership studies that embraces a focus on cultural and linguistic multiplicity. In between reviewing these two streams, we also make space to summarise an emergent third area of scholarship: critiques of crosscultural leadership research.

\section{Etic, cross-cultural leadership studies}

Based on the literature searches we have conducted - and in line with insights from previous reviews (e.g. Dorfman 2004; Guthey and Jackson 2011; Zhang et al. 2012) - it seems that the field of cultural leadership studies continues to be dominated by a fundamentally etic approach to studying cultures and by the understanding of culture as national culture. This approach is looking into a culture or cultures from an apparently outside perspective, seemingly objectively and in an unbiased way while in actuality being a decidedly western and predominantly Anglocentric perspective (Turnbull 2009; Guthey and Jackson 2011; Turnbull et al. 2012). It takes a dominant position in the leadership discourse of mainstream textbooks used in academic and leadership development settings as well as in the leading leadership journals (e.g. Scandura and Dorfman 2004; Wasti et al. 2007; Jung and Avolio 2009). Indeed, Zhang et al.'s (2012: 1065) recent review of 285 articles published in The Leadership Quarterly between 2007 and 2012 
showed that $73 \%$ of studies were 'conducted in the US' (and hence actually represented 'indigenous US studies', although the studies lacked any recognition of their specificity). They also showed that the other $25 \%$ of studies were using concepts and 'theories that were developed in the US or other Western countries' (Zhang et al. 2012: 1065), suggesting imposition of Western concepts based on Western cultures onto local, indigenous contexts rather than exploring locally meaningful practices and conceptualisations of leadership. Only $2 \%$ (five studies) were truly indigenous studies, i.e. conducted by local researchers within the local context using the local language.

Our review further reveals that - working from within the traditional, psychological perspective of leadership research - empirical studies take a distinctly cross-cultural approach in the sense that they have drawn on essentialist, functional models of culture (notably based on Hofstede 1980, 1993) and leadership (e.g. contingency theories, implicit leadership theories and leader-member-exchange theories) to ascertain either universal or culturally contingent leadership behaviours with a view to comparing and contrasting different cultures (e.g. Kakabadse et al. 1996; Suutari 1996, 1998; Jung and Avolio 1999; Brodbeck et al. 2000, 2002; Egri and Herman 2000; Ardichvilli and Kuchinke 2002; Schneider and Littrell 2003; Hamlin 2005; McCarthy 2005; Wasti et al. 2007; Wendt et al. 2009; Sadri et al. 2011; Martin et al. 2013; Lee et al. 2014; Cheng et al. 2015). This research paradigm is exclusively focussed on the leader and the effectiveness of his/her behaviours, situating empirical studies firmly within psychometric traditions.

The popularity of this etic approach was further enhanced through the success of the GLOBE project, involving large-scale quantitative analyses of cultural values and leadership preferences of over 17,000 managers in 951 organisations across 62 national cultures (House et 
al. 2004) and further in-depth analyses of 25 of the 62 national cultures (Chokar et al. 2008). Grouping the 62 nations into 10 cultural clusters, the GLOBE project showed strong similarities within cultural and leadership preferences across societies within each cultural cluster. Recent cross-cultural studies continue to make reference to the GLOBE project, as is exemplified by Martin et al.'s (2013) comparison of the meaning of leader integrity in and across Ireland, the US, Germany, Austria, China and Hong Kong - representing three of the GLOBE clusters (Anglo, Germanic Europe and Confucian Asia). Drawing on online questionnaire data from a sample of 189 managers, this research continues the tradition of examining meaning and effectiveness of leader behaviour and attributes across cultures to determine both universal and culturally contingent patterns. Whilst it professes to recognise the importance of language and employs thematic analysis to explore the meaning of 'leader integrity', it followed the standard, cross-cultural translation and back-translation process to create its German and Chinese questionnaires.

GLOBE project type of research has been particularly popular thanks to the insights it seems to bring for cultural sensitivity programmes for global leadership and expatriate management programmes in organisations. It is recognised to have made a significant scholarly contribution (Dansereau and Yammarino 2006; Dickson et al. 2006; Hanges and Dickson 2006; Peterson and Castro 2006) by addressing such fundamental questions as whether there is a link between leadership and culture, and if there is a link what it means for predicting effective leadership behaviours within specific cultural contexts (Guthey and Jackson 2011).

Yet, taking an essentialist approach to culture has meant that cultural boundaries are usually associated with a geographical 'country of origin' (Altman and Laguecir 2012), limiting our understanding of multiple cultural memberships of one person or a group, the multiplicity of 
cultures in one geographic location and changes in cultures and cultural membership over time. This focus on national (geographical) categorisation of culturally dependent leader behaviours mirrors and perpetuates the focus of mainstream leadership discourse on effectiveness and implicitly assumes that leaders and followers can be categorised into one distinct culture.

\section{Critical views on cross-cultural leadership studies}

From our literature review, we can see that the last decade has seen an increase in critiques of the dominant etic, cross-cultural approach (Graen 2006; Ooi 2007; Jepson 2009; Clausen 2010; Guthey and Jackson 2011). These critical contributions argue that the continuing drive towards generalisation and universal models of cultural leadership fundamentally limits our ability to investigate the complex relationships between leadership and culture by ignoring difference, variation, multiplicity and historicity within and across cultures.

Jepson's (2009) critical review of the GLOBE project and its fundamental approach to studying leadership across cultures, for example, draws out key conceptual and methodological limitations in the project and warns of potential misrepresentations of local, culture-specific leadership behaviours. A key limitation of cross-cultural leadership research exemplified by the GLOBE project, she argues, is the use of the quantitative questionnaire tool that allows only for explanation, not exploration, hence creating variables and measures rooted in the English language and reflect the implicit Anglo cultures that underpin them. As a result, Western and predominantly Anglo thought and theory and English language conceptual frameworks and meanings are imposed onto local cultures through a fixed research framework. Such an approach does not allow open exploration of local cultures from within. 
Further limitations lie in the oversimplified and static measure of national culture as well as the treatment of language as a homogenous (Steyaert and Janssens 2013) and neutral (Jepson 2009) tool for information transmission. This assumed homogeneity and neutrality of language is problematic in light of Agar's (1994) work on Languaculture and subsequent contributions by linguistic relativity scholars (e.g. Lucy 2000; Slobin 2000) that have shown that 'language and meaning are not only inseparable from each other but also from culture' (Jepson 2010: 428). This body of work stresses the importance of seeing language as a cultural voice (Tietze et al. 2003) and suggests that the 'mother tongue' resembles a 'comfort zone' within which the individual converses in his/her own meaning system (Tietze et al. 2003). Recognising the existence and importance of cultural codes and meaning systems of languages also allows for greater sensitivity to multiplicity within languages and the political processes embedded in language use (Steyaert and Janssens 2013).

McSweeney (2002), Tayeb (2001) and Clausen (2010) further highlight that through the assumption that culture is the mental programming of the mind (Hofstede, 1980), and hence stable, cross-cultural studies (such as Brodbeck et al. 2002; House et al. 2004; Martin et al. 2013) have proposed that they can draw generalisations on patterns across cultures. In effect, such studies have created or reinforced rather than replaced and dismantled stereotypes attached to groups and populations and they have led to the thinking that cultural encounters are predictable, fixed and even predetermined. Ailon (2008) and Ooi (2007) stress that these stereotypes perpetuate dominant, western images (with imperialist and colonial histories) of local cultures, bearing the cultural, socio-political imprint of those researching them and the dominant funding and publication regimes they are adhering to. 
Linked to this critical debate, Collinson $(2005,2014)$ has for some time argued that leadership studies as a field is populated with dualisms leading to a strong focus on dichotomisation, without critical reflections on the negative impact this has. He draws up a list of such dualisms including that of leadership/management, transformational/transactional to illustrate the dominant presence of dichotomies and posits that

'Dichotomisation constrains analysis by over-simplifying the complex, interconnected, and shifting relationships that characterize leadership dynamics. It emphasizes differences by making successive separations between distinctions and treating these as immutable polarities. Dichotomisation involves simultaneous and asymmetrical processes of privileging, marginalizing, and excluding. Furthermore, it tends to narrow down the range of concepts, issues, and variables as well as limiting and fixing their causal direction. As a result, important issues, particularly around power, ambiguity, tension, paradox, and contradiction tend to disappear from view.' (2014: 39)

This tendency for simplified dichotomies has masked the true complexity and dynamics of the phenomenon of leadership (Collinson 2014), arguably in favour of saleable managerialist formulae of leader effectiveness. Our review of the dominant stream of etic, cross-cultural research, utilising essentialist models of culture shows that it has embraced this focus on dichotomisation and effectiveness. It has continuously reinforced fundamental distinctions between culture-specific and universal leadership styles and polarised through the development of culture-specific leadership styles the extent to which one belongs or does not belong to a 
particular cultural category and therefore desires a particular leadership style. This seemingly marginalises and excludes multiplicity within a given cultural and linguistic context and counteracts explorations of intra- and inter-connections, tensions and paradox within and between cultural categories and the dichotomisation of culture-specific vs. universal leadership styles.

With a view to multiplicity in languages, our review suggests that cross-cultural research has worked towards reinforcing national stereotypes from a western perspective and failed to recognise and explore power processes, ambiguity and paradox in multilingual contexts (see Ahonen et al. 2014). The hegemony of this dominant approach to studying leadership and culture has further hindered the voice of alternative forms of cultural study through its dominance in academic journals. We therefore propose that it is of importance to make space for alternative research that explores the blurred lines between dichotomies and categories so as to recognise that leadership can be both universal and culture-specific.

\section{Emic, non-positivist studies on leadership and culture}

In light of the many critical views present in the literature (e.g. Jepson 2009; Clausen 2010; Guthey and Jackson 2011) that highlight the conceptual and methodological limitations of the cross-cultural dominance within the field of cultural leadership studies, scholars like Clausen (2010: 57) advocate research 'rooted in the social constructivist paradigm, in which culture concerns the construction of meaning and its negotiation in social encounters'. Her research supports similar arguments by Zhang et al. (2012) and Jepson (2009) that qualitative, social constructionist approaches to cultural research enable the uncovering of indigenous leadership 
and management practices and allow an exploration of the dynamic evolvement of cultural encounters.

As a result, our review shows that the last decade has seen a surge of non-positivist cultural research into leadership in indigenous communities and practices (Warner and Grint 2006; Campbell 2008; Bolden and Kirk 2009; Islam 2009; Neal and Tansey 2010; Riad 2011; Sveiby 2011; Yang 2011; Turnbull et al. 2012; Zhang et al. 2012), studies using a communicative approach (Lin and Clair 2007; Brummans and Hwang 2010; Xu 2011) and/or focussing on different languages (Prince 2006; Jepson 2010) and research exploring the historicity of language and culture (Peltonen 2012). Postcolonial critiques, increasingly popular in other fields of management studies (see Jack et al. 2011), are also beginning to emerge (Nkomo 2011; Srinivas 2013), building on an existing but not well known body of literature on non-western forms of leadership (see e.g. Fourie et al. 2015). Based on our review, we can see that such research is able to ask different, localised and in-depth questions and explore dynamics, tensions, intra- and inter-relationships in a way that etic, cross-cultural studies cannot explore or explain.

Starting with indigenous studies of leadership, we reviewed research focussed on the exploration of indigenous peoples, languages, knowledge and forms of leadership. Studies falling within this definition are still quite rare and we found the term 'indigenous' also being referred to more generically in the literature with reference to empirical studies of leadership within nonWestern contexts (e.g. Campbell 2008; Bolden and Kirk 2009; Neal and Tansey 2010). Both forms of indigenous leadership studies usually still make references to Anglo framings of leadership in order to get published in journals (e.g. Sveiby 2011). For example, Warner and Grint (2006), utilise their own different heritage - Comanche and Anglo - and rich qualitative, longitudinal data with American Indians to explore leadership patterns amongst these indigenous 
peoples that do not fit with traditional western leadership models. In this indigenous research study, Warner and Grint (2006) engage deeply with indigenous languages, knowledge and historical contexts to discuss the importance of the notion of 'serving the community' within American Indian leadership. Sveiby (2011), on the other hand, uses indigenous stories as a data source, including traditional law stories and anthropological accounts, to explore collective notions of leadership within Australian Aboriginal knowledge. Unlike Warner and Grint (2006), his interpretation of this data in relation to leadership beliefs and practices is then framed by the functionalist DAC ontology developed by Drath et al. (2008), instead of working more closely with indigenous meanings and connotations. This leads Sveiby (2011) to develop a generic framework for collective leadership based on one of the analysed Australian Aboriginal law stories. A historical case study method similar to that of Sveiby (2011) was employed by Neal and Tansey (2010) in their effort to examine effective corrupt leadership in Lebanon and by Campbell (2008) to discuss forms of religious leadership in Islamic contexts.

As noted above, within this growing field of non-positivist cultural research, our review revealed that there has been some interest in exploring culture and leadership through a linguistic lens. Jepson's (2010) research, for example, approaches language as the basis for understanding a socially constructed concept such as leadership and looks into the importance of national language as a cultural voice that not only sets fundamental boundaries to the way we talk about leadership but also influences the way we theorise and subsequently enact leadership (Tayeb 2001). Working with German language expressions (Mueller 2007) across a large set of interviews with German employees and managers in the German Chemical Industry, Jepson (2010) was able to explore in detail culturally embedded meanings of these language expressions and demonstrate their dynamic and diverse nature. The cultural reading of these accounts further 
helped to highlight possible linguistic misrepresentations of previous cross-cultural studies on leadership and management in a German context (Jepson 2010).

The importance of such research into linguistic multiplicity as a means to exploring culturally embedded practice is further supported by research such as Prince's (2006) work on Taoism, Schedlitzki et al.'s (2013) exploration of the Welsh language, Julien et al.'s (2010) study of Canadian aboriginal leaders and Peltonen's (2012) conceptual history of management/leadership in Finland. The close examination of language and communication within these studies allows the researchers to highlight culturally embedded, fundamental differences in meaning and practice of leadership between these specific linguistic and cultural contexts and mainstream, Western leadership theories.

Schedlitzki et al. (2013), for example, used word cards as a projective technique in their interviews to elicit discussion of different meanings of Welsh and English words connected to leadership and management. This helped to uncover emotive and power-based dimensions of these language expressions in use within multilingual work contexts. Julien et al. (2010), on the other hand, were able to highlight through their use of qualitative interviews not only the more long-term and community focussed beliefs but also the indirect style of communication that Canadian aboriginal leaders embrace and that draws on traditional imagery, story-telling and animal-based metaphors. The decision to use a qualitative methodology was particularly driven by the researchers' desire to 'use research methodologies consistent with the cultural values' of the sample (Julien et al. 2010: 117). Hence they saw interviews to be 'harmonious with the traditional aboriginal practices of story-telling and building strong long-term personal relationship' (Julien et al. 2010: 117). The flexible and open-ended nature of interviews further allowed them to explore the holistic perspective, central to aboriginal culture, that was 
previously identified by Redpath and Nielsen (1997) to be omitted by etic research utilising predetermined Western culture-frameworks such as Hofstede's (1993).

Other discursive research studies taking a social constructionist or critical approach have also helped to stress the importance of embracing conceptual multiplicity by highlighting the relational, interconnected and yet often contradictory and both local and translocal nature of leadership, discourse and culture (e.g. Koivunen 2007).

Finally, the historical turn in management research during the last decade has emphasised the importance of cultural and historical specificity in management theory and practice (Weatherbee 2012; Rowlinson and Hassard 2013; Vaara and Lamberg 2015). Research into conceptual history, building on the work of Koselleck (2002), traces the emergence, relations of meaning and ways of using key concepts in any given time. The aim of conceptual history is not to trace the history of ideas but to make visible the ways in which historically dynamic and changing concepts have influenced and constituted phenomena over time. Peltonen's (2012) study of management textbooks in Finland in the 1950s shows, for example, that the Finnish concept ‘johtaminen' ('management, managing') was not widely used in the books. Instead, concepts such as 'hoito' ('care, conduct'), 'johto' ('leadership, management') and 'hallinta' ('control, handling') were employed to denote the administrative phenomenon. What this kind of research shows is that concepts do not only differ in terms of language but also in terms of history. Yet, so far we have only gained some insight into the history of the English-based terms leader, leadership and manager, management (Grint 2010; Case et al. 2011). We hence argue that there is still much research to be done into the history of local, culture-specific concepts in relation to ways of leading, managing and directing that are rooted in languages other than English. 
From our review, we can see that the main advantage of taking an emic, non-essentialist approach to cultural leadership research is that it allows for sensitivity to the multiplicity of local languages as multifaceted cultural voices. It also symbolises a move away from a hegemonic, colonial perspective that defines parameters of study and evaluation of local cultures and a move away from perpetuating stereotypes that fit the researcher's mental models of communication and own agenda. By embracing a social constructionist and/or critical approach to cultural leadership studies, these studies are able to 'recognise the co-constructed nature of organisations and leadership processes' and able to 'place more emphasis on the promotion of dissent, difference, and the facilitation of alternative viewpoints' (Tourish 2014: 81) rather than promoting consensus over culture and leadership style categories. Indeed, Tourish (2014: 81) argues 'that there is no essence of leadership divorced from particular social, organisational and temporal contexts', ultimately challenging the fundamental dichotomisation of universal vs. cultural-contingent leadership behaviours ever present in cross-cultural leadership studies. Embracing a social constructionist approach to studying leadership and culture enables cultural leadership research to move beyond dichotomisation by exploring to what extent leadership behaviours can be both universal and culturally contingent. This opens the field up to dialectic investigations into how universal and culturally contingent leadership behaviours 'may be mutually reinforcing and/or might cut across and be in tension with one another' (Collinson 2005: 1434).

\section{Leadership and language multiplicity: an alternative research agenda for cultural leadership studies}


This new stream of emic, non-positivist research currently lacks in voice and impact compared to the still dominant cross-cultural discourse. Building on our critical review of the cultural leadership research field, we therefore argue for a move away from purely essentialist, etic approaches to studying leadership across different cultures and towards a focus that embraces differences, similarities and interactions within and between cultures. This, we argue, will enable us to ask different questions from those addressed in the cross-cultural leadership literature and focus further on multiplicity, power dynamics and paradoxes (Ahonen et al. 2014). With a view to methodologies, this further warrants a stronger focus on social constructionist rather than predominantly positivist approaches to cultural leadership studies (Zhang et al. 2012; Parry et al. 2014) and recognition that cultures are not stable and definite but evolving, multiple and shifting. Our review has shown that focussing specifically on explorations of language as a cultural voice enables such greater sensitivity to multiplicity and historicity of cultures, enabling cultural leadership studies to overcome previous tendencies for simplification, dichotomisation and stereotyping.

Our call for a revised research agenda in cultural leadership studies focussed on language multiplicity complements other calls for communicative (Fairhurst and Connaughton 2014; Tourish 2014) and discursive leadership studies (Fairhurst and Uhl-Bien 2012). The main aims of a language multiplicity and leadership research agenda for cultural leadership studies are:

- to pay attention and give voice to cultural and linguistic multiplicity by exploring variations in representations and conceptualisations of leadership within and across different linguistic and socio-cultural settings.

- to explore the political and historical development of representations and conceptualisations of leadership within and across different linguistic and socio-cultural settings. 
- to embrace a non-essentialist approach to studying leadership and culture that utilises methods that are sensitive to language and cultural multiplicity.

- to open up a space for explorations of different, culturally meaningful conceptualisations and organisational practices that go beyond the assumed conceptual relationship between leadership and management in mainstream discourse.

Based on our review, we argue that a focus on language multiplicity will encourage truly indigenous contributions that explore the representations and conceptualisations of ways of leading, guiding, governing, conducting and directing of and in organisations without presuming and imposing non-indigenous theories. This should then involve examining the political, historical and cultural roots of 'leadership' within specific national, professional, regional and organisational languages as well as the influence of the English language as an assumed, homogenous business and scholarly lingua franca. Explorations of culture through the lens of language and discourse further help us to overcome the previously highlighted limitations of essentialist approaches to culture (Ailon-Souday and Kunda 2003; Altman and Laguecir 2012) that are tied to fixed cultural memberships and geographical boundaries, promoting cultural stereotypes and essentialist dichotomies (Collinson 2014). The focus on language multiplicity allows us to recognise and seek meaning from linguistic variation as a means to exploring cultural multiplicity.

To counteract the promotion of a homogenous, unreflective use of any specific mother tongue, we further call for studies to explore local languages as 'the result of a political process (where) power, domination, negotiation and forms of resistance are core ingredients of the way language is performed' (Steyaert and Janssens 2013: 133). Exploring language use in 
organisations through the lens of multiplicity may also help to shed light on cultural tensions between leader and follower identities that go beyond mere cultural categorisation and enable us to explore in detail cultural inter-relationships.

This new research may then help to further contextualise the meaning and importance of leadership and leadership development as well as give voice to community-based and historically and culturally informed understandings of leadership in organisations and society. Not only will this work towards breaking down cultural barriers within international workplaces but also enrich learning on leadership in organisations within and across cultures. By taking a social constructionist approach focussed on cultural and language multiplicity, this research agenda further embraces and helps to explore leadership as a 'sense-making' process (Pye 2005). This enables the exploration of "potential struggles over meaning wrought by diverging relational, organizational, or socio-historical influences' (Fairhurst and Uhl-Bien 2012: 1046), providing a needed counter-balance to the consensus driven dichotomisation of universal and culturally contingent leadership behaviours in the cross-cultural research studies tradition.

We identify below methodological approaches conducive to contributing to this research agenda at different levels of analysis and enrich this discussion through specific examples of existing contributions and potential future research avenues.

\section{Methodological Approaches}

Based on our critical review of different methodological approaches to studying culture and leadership, we see a move away from purely essentialist, etic approaches to studying leadership across different cultures as essential for the success of this leadership and language multiplicity 
research agenda for cultural leadership studies. Our argument is similar to that of Zhang et al. (2012) in that we argue that we need methods that allow us to pay attention to the intricate webs of signification (Geertz 1973) in a cultural setting and seek deep understanding of the variations in conceptual meaning and history of leading within this culture as well as possible interactions with other cultures. Unlike Zhang et al.'s (2012) aim to combine positivist and constructionist traditions in a multi methodological framework, we argue that in order to avoid simplistic and homogenised models of leadership, we need to move firmly towards a social constructionist approach to cultural leadership studies that recognises cultures to be multiple and evolving, i.e. rigid, immobile and historically solid in some aspects and mobile, flexible and changing in others.

Aligning ourselves with meaning-centred communicative studies of leadership (see Fairhurst and Connaughton 2014 for review), we suggest that methodologies used within our proposed research agenda need to see and explore leadership, culture and language use as relational, diverse, power-based and dynamic. Hence, we suggest that future research embracing an emic, constructionist approach to cultural leadership studies should also take this opportunity to engage in more diverse and culturally as well as linguistically sensitive research methods. As such these research methods need to be able to focus on social and symbolic meaning, seek to explore and be able to 'follow unexpected ideas' (Parry et al. 2014: 133), rooting this research agenda firmly in the field of qualitative research.

Apart from a concurrent call for more qualitative research (Bryman et al. 1988; Bryman et al. 1996; Conger 1998; Bryman 2004; Parry et al. 2014), the field of leadership studies has also for some time now been criticised for being too singularly focussed on interviews and questionnaires as the main or often only method of data collection (Bryman 2011). In moving towards a wider 
range of culturally and linguistically sensitive methods, leadership studies may hence look towards the fields of linguistics, inter-cultural communication, anthropology and history to forge cross-disciplinary collaborations and learn from research practices within these fields. Research methods employed within our proposed language centred research agenda may include ethnographies (e.g. Maitlis and Lawrence 2007), auto-ethnographies (e.g. Kempster and Stewart 2010), dialogical and discursive analyses (e.g. Alvesson and Sveningsson 2003; Fairhurst 2011; Fairhurst and Uhl-Bien 2012) as well as aesthetically informed (see Hansen and Bathurst 2011) and visual or arts-based enquiries (see Taylor and Ladkin 2009; Schedlitzki et al. 2013; Schyns et al. 2013).

Ethnographies and auto-ethnographies would enable the exploration of the fluid and changing nature of individuals' or groups' understanding and practice of leadership and management. Maitlis and Lawrence's (2007) use of ethnography - including interviews, observations and documentary analysis - to follow sensegiving processes in real time over two years and in three organisations demonstrates how this type of method allows in-depth analyses of processes and actors involved as well as attention paid to dynamics, comparisons and diversity. Such use of ethnography may shed further light on the changing and interactional nature and impact of different cultures on the individual's or group's sense-making of leadership. This overcomes the previously identified limitations of cross-cultural research studies and their essentialist, static approach to culture where cultural membership is predominantly treated as definite and largely tied to a geographical country of origin (Tayeb 2001; McSweeney 2002; Ailon-Souday and Kunda 2003; Altman and Laguecir 2012). Adding an auto-ethnographic element to such cultural research may further help 'to illuminate the experience of history' and 
process through the actors' narratives, as Kempster and Stewart (2010) showed in their analysis of leadership learning as a process of critical reflection on experiences in situ.

Dialogical or discursive analyses would enable us to further explore multiplicity of specific conceptual meanings and highlight political and gendered, racialized and other power relations and processes at play in language use within and across specific local, cultural contexts. Koivunen (2007), for example, has used discourse analysis to demonstrate the processual and paradoxical nature of leadership discourses by exploring the relational, contradictory and translocal nature of leadership discourses in symphony orchestras in Finland and the United States. Taking a processual approach and focussing on how individuals 'make their world understandable to themselves and to others' (Koivunen 2007: 288) through language will allow cultural leadership studies to question existing assumptions of cultural determinism (McSweeney 2002; Ailon 2008), work against tendencies to perpetuate cultural stereotypes through fixed cultural categories and instead explore inter-relationships, tensions and paradoxes. Finally, aesthetic enquiries engaging with sensory knowledge and emotions would add to our cultural understanding of leadership as an embodied practice (Ropo et al. 2002). So far, aesthetic enquiries have predominantly been focussed on conceptualisations of leadership (e.g. Pye 2005; Ladkin 2006, 2008) and as a means to enrich leadership development practice (e.g. Sutherland 2013; Edwards et al. 2015; Schedlitzki et al. 2015). Drawing particularly on the insights from this body of work around storytelling, sense-making and projective techniques would help to complement discursively focussed approaches by tapping not only into thought but also emotion and feelings and should as such be part of ethnographic projects contributing to our proposed leadership and language multiplicity research agenda. 
Insert Table 1 about here

Table 1 shows how a combination of these methods will enable researchers to advance the field of cultural leadership studies by focussing on generating detailed analyses of cultural and linguistic multiplicity and encouraging researcher reflexivity. Below, we will discuss in detail some of the specific suggestions for future research projects within this leadership and language multiplicity research agenda as summarised in Table 1 . The methods we have chosen here are not an exclusive list but rather examples of the type of linguistically and culturally sensitive methods that are likely to meet the aims of our proposed research agenda and overcome some of the previously identified limitations of existing cross-cultural leadership research. To capture the range of linguistic and cultural multiplicity present in a given region and/or workplace, research may work at a micro and/or macro level of study. Bearing further in mind that the particular contexts we choose to research will be fluid and changing over time, it seems of utmost importance to employ historical or longitudinal as well as in-depth focussed data collection methods. We will also discuss and highlight the great importance of designing data analysis and findings dissemination processes that are equally sensitive to and reflective of local culturally and linguistically informed meaning. This is to be aware of and work with possible mistranslations and to acknowledge subjective interpretations as a natural part of the research process (Ailon 2008).

\section{Macro-level investigations}

At a macro-level of analysis, at the level of general language use and broadly shared meanings, researchers working within our proposed research agenda may wish to explore a 
specific multilingual context by giving voice to variations in words and meaning used in connection with leadership within and between different official languages and dialects. Akin to Schedlitzki et al. (2013), they could explore the use and history of meanings of specific notions associated with phenomena that in the English language are captured by such terms as 'leader', 'manager', 'leadership', 'management', 'conductor and 'governing'. It is important to bear in mind that any insights gained into possible meanings of leadership are tied to the very dynamics of the sample gathered and research team involved.

Rather than imposing a semi-structured format that is so dominant within current leadership studies, we therefore suggest engaging with a set of creative and projective techniques (Goetz and LeComte 1984; Taylor and Ladkin 2009), such as the use of word cards (Schedlitzki et al. 2013) and cultural artefacts (e.g. images, paintings, myths, stories or poetry), to encourage an open, interactive discussion. Words often associated with leadership and management could be displayed on cards and, together with cultural artefacts brought along by participants, used as a way to trigger discussion on the meaning and practical use of words related to leadership and management in organisational life. Empty cards could further be provided as spaces for participants to write down particular words that are meaningful within their language and related to processes of organising, leading or managing. Providing such artefacts as triggers for interactive discussions may help in accessing inner feelings, experiences and meaning associated with particular words and abstract concepts (Goetz and LeComte 1984; Schyns et al. 2013).

The projective (Goetz and LeCompte, 1984) word card technique was used successfully in the afore-mentioned exploratory study into the Welsh language (see Schedlitzki et al. 2013 for a full discussion) and it enabled a rich insight into emotional and culturally embedded meanings of language-in-use. Stephens (2003 p. 48) has also demonstrated how working with the story of a 
female mentor helped participants to access and recover hidden memories of female leaders that were without such 'flooding of the imagination' lost in the gendered language of traditional leadership discourse. Participants could further be encouraged to create individual or shared artefacts to capture the essence of the discussions that take place. Schyns et al. (2013) have, for example, asked participants to draw images of leaders to tap into their implicit leadership theories. With a view to our cultural leadership research agenda, we advocate the use of such aesthetic tools to evoke a similar flooding of the imagination to bring to the fore hidden notions of leadership in indigenous communities and to capture the creation of shared new meanings of leadership as part of the research process.

These open discussions could then be followed up with more targeted questions about the participant's work context to enable the individual to access memories of experiences (see Stephens 2003) that may to date have not been associated with leadership in light of the dominance of English language specific terms. Working with the so far hidden images of culturally rooted leadership and any artefacts produced in situ may help to stabilise such images alongside the dominant mainstream ones. To add a longitudinal element to this type of research, these conversations could be conducted at long intervals over 5-10 years to also capture changes within shared and individual meaning.

An auto-ethnographic element - for example in the form of reflective diaries - could be added to capture participants' episodic reflections on the initial meaning-making process and subsequent engagement with indigenous language, knowledge and artefacts over the course of a few months. This could also facilitate the analysis of local variations in meaning of representations of leadership. A key aim here would be to uncover multiplicity in language use within and across the official languages and for the research team to reflect carefully on and 
work against any potential tendencies to generalise or homogenise across the sample of participants. Acknowledging multiplicity may then provide opportunities to explore how such local variations are tied to gender, age, ethnicity and membership in social groups such as the profession, the organisation, the immediate work team or private life of participants.

It is through these reflections on multiplicity and local variations that this type of research diverts significantly from other indigenous leadership frameworks (e.g. Zhang et al. 2012) that have so far tended to aim for the development of generalisable, indigenous leadership models. It allows us to, not only compare languages, but more importantly explore through a focus on local variations the power play of active language use and hence helps to gain further understanding of how languages may be inter-related and indeed create tensions within a multilingual organisational setting.

\section{Micro-level investigations}

A micro-level analysis within the leadership and language multiplicity research agenda explores local, sub-cultural and organisational variations in meanings and power dynamics of language use within an official language or dialect and seeks to explore interrelationships with other discourses. Conducting organisational ethnographies in a selection of settings, such as a small work team, a small organisation or a selection of employees within a larger organisation, will enable such insight into cultural and language multiplicity. Through observations, conversations, reflective diaries etc., the research team would aim to gain an in-depth understanding of particular local uses and interpretations of words and meanings connected to leadership and sense-making and sense-giving processes. As Maitlis and Lawrence (2007) have shown, such ethnographic work is able to tap into the sense-making and sense-giving processes 
of individuals and groups and discursive analysis of such accounts enable the exploration of possible tensions that the existence and use of different languages, dialects and discourses may create for employees (Koivunen 2007). Koivunen (2007) and Jepson's (2010) language based analyses, for example, were able to access the local and translocal meanings of leadership within and across different cultural contexts, highlighting the multilingual and paradoxical nature of language. Paying attention to processes of language use in such organisational contexts will also help to shed further light on the 'interplay and hierarchy between languages' (Steyaert and Janssens 2013: 133) adding to our understanding of the complexity of communication between leaders and followers. Engaging further in the use of aesthetically informed, visual or arts-based techniques will encourage reflection on specific, local meaning-making processes and add to our cultural understanding of leadership as embodied practice (Ropo et al. 2002; Taylor and Ladkin 2009; Hansen and Bathurst 2011)

Such insights are arguably crucial for the emerging perspectives of leadership that see 'leadership as a relational process co-created by leaders and followers in context' (Fairhurst and Uhl-Bien 2012: 1044) as it helps to highlight the cultural, historical, institutional and political dimensions of this context (Steyaert and Janssens 2013). These multilingual complexities, we argue will be particularly prevalent in multilingual organisational contexts where professional, organisational discourses interplay with several languages. To date, cross-cultural leadership studies have failed to explore such local discursive variations and tensions, exaggerating the influence of national culture on preferred leadership practices.

Making sense of the data

Page 35 of 62 
The field of translation studies (see Steyaert and Janssens 2013) has long recognised the potential for monopolisation of 'complex cultural and linguistic material (...) by a single language' (Snell-Hornby 2010: 102) and the damage this can do to locally meaningful enquiries. Meyer and Boxenbaum (2010) have referred to the marginalisation of non-English intellectual traditions due to unreflective translations into English during the publication process. Postmodern enquiries that 'acknowledge that meaning is jointly constructed with participants (Parry et al. 2014: 133) could help to shed light on the political processes in doing language research and particularly the dangers in translating research findings into the dominant language of publication. Steyaert and Janssens (2013) warn that a problem often highlighted in translation studies occurs when researchers 'translate data themselves without making possible ambiguities part of the set up and reflection of the article, giving in to some kind of essentialist codeswitching' (136). Based on our review, we would add that other influences such as gender, ethnicity, age and funding routes may influence the power dynamics at work and argue that researchers doing this type of research need to engage in some form of critical reflection and an open dialogue process between researchers throughout the project and particularly at the translation stage to enable more insightful analyses and subsequently for culturally and linguistically sensitive accounts to be disseminated.

We have already highlighted above, and with reference to insights from the field of translation studies (see Steyaert and Janssens 2013), concerns with translations across languages. It is of utmost importance for research like this to acknowledge the likelihood of individual interpretations and bias in the research process but also explore ways in which local meaning can be maintained whilst disseminating findings in a single, different language. Throughout the data gathering process, it may be particularly important to have several native speakers from within 
the research team involved at any stage. These members of the research team can then through conversation after each intervention explore each other's views and interpretations of the participants' responses and through such open dialogue encourage critical self-reflection (Reynolds 1999) and attempt to work against any dominant individual interpretations and bias taking over. This would enable the research team to hold onto ambiguities, tensions and paradoxes found within the data and counteract tendencies to homogenise findings. Welch and Piekkari (2006) further highlight the potential power dynamics between researchers and the danger of power asymmetry and control over the data when one researcher is fluent in more languages than others in the team. This needs to be actively addressed and processes established that counteract the existence and/or potentially negative impact of such power asymmetry.

In addition to this meaning-making work during the data gathering process, it is then equally crucial to have an open dialogue approach (Bakhtin 1996, 2002) to the data analysis and dissemination process. This can happen within a team of researchers with the same mother tongue, but given the dominance of the English language as the academic lingua franca, will also need to include English speaking researchers. These researchers will need to be engaged with the field of leadership studies and particularly experienced in this type of culturally and linguistically sensitive research. An appreciation of social, historical and political dimensions of language and culture will be further important. Through dialogic sessions with native speakers and non-native speakers, the research team can then start to make sense of the data in relation to existing knowledge on the subject of leadership and management in order to identify conceptually and empirically indigenous contributions arising from the data. A series of such sense-making sessions will enable the dissemination of findings and contributions in the English language in a way that does not compromise but rather embraces the native language specific words and 
meanings. Mueller (2007) suggests, for example, working with source-language expressions to avoid monopolisation by the English language. Venuti (1998) further suggests making explicit the ambiguities and choices made within the translation process in the written work to highlight the reflective process that the research team has undergone.

\section{Conclusion}

This critical examination has identified and evaluated different conceptual and methodological approaches present within the cultural leadership literature. We have argued that the dominant etic, cross-cultural approach and its essentialist treatment of culture and language presents a significant risk for misinterpretation of the meaning and existence of leadership in other languages as well as the marginalisation of other linguistically meaningful organisational concepts. Drawing on insights from the inter-cultural communications and management literature in relation to etic and emic cultural research, we have shown that the field of cultural leadership studies would benefit from an alternative research agenda focused on language multiplicity. Existing emic, non-positivist research (e.g. Koivunen 2007; Jepson 2010; Julien et al. 2010; Schedlitzki et al. 2013) has demonstrated that a focus on the multiplicity of local languages allows us to capture more adequately the complex, dynamic nature of culture and its relationship to meanings and existence of leadership. Further emic research is needed to strengthen this research voice and enable it to gain a foothold in the dominant leadership discourse.

To this end, we propose that a research agenda focussed on language multiplicity will enable the field to empower non-Anglo-American, non-Anglicised, and indigenous, leadership language 
and conceptualisations. We believe that a shift towards this cultural research agenda will be able to work on breaking down existing fixed cultural categories and readily available stereotypes in leadership studies and organisational practice. Linguistically, culturally, and historically sensitive studies within this proposed research agenda will be able to bring new and locally valued insights into a field that has started to become too static and tied to its western, psychometric roots and assumptions about leadership in organisations through careful exploration of interrelationships, power dynamics, tensions and paradoxes.

In support of this new research agenda for the field of cultural leadership studies, we have offered some methodological suggestions and propose the use of different kinds of culturally and linguistically sensitive data collection methods. The methodological approaches we have identified can be deployed under a number of different theoretical frameworks, from PaleoMarxism to Actor-Network Theory and beyond. We have particularly highlighted the benefits of using a mix of aesthetic methods (Hansen and Bathurst 2011), dialogic interventions (Fairhurst 2011), discursive analyses (Koivunen 2007), auto-ethnographic diaries (Kempster and Stewart 2010) and ethnographic research (Maitlis and Lawrence 2007) projects as a means of gaining indepth as well as longitudinal insights into cultural multiplicity in representations of leadership and management within and across different languages and discourses. Drawing on the field of translation studies, we further propose that it is important to be aware of the role of the research team within both data collection and meaning-making processes. We have argued that there is a real need for multiple native speakers to be present at any stage of data collection and an open dialogue (Bakhtin 1996, 2002) to be encouraged between these researchers so as to foster critical self-reflection (Reynolds 1999) on power dynamics in the translation process (e.g. gender, ethnicity, language, age and/or funding streams); and counteract the dominance of any one 
specific interpretation of the participant accounts. In recognition of the pressure to disseminate findings in the English language and in recognition of existing concepts of leadership written in the English language, we have further suggested a final stage of sense-making where non-native speakers with expertise in leadership studies are involved to enable an analysis and dissemination into English speaking academic communities that does not sacrifice but embraces local meanings.

To conclude, we are not proposing to supplement existing, Anglo-centric research dominated by Anglo-American researchers and research institutions. Cultural leadership studies, as we understand them, are not an adornment to be added to the canon of leadership knowledge. What we are proposing is a rethinking of the whole canon, its assumptions and the ways in which it produces knowledge about those who lead and of ways of leading. Cultural leadership studies should provincialize the dominant Anglo-American leadership knowledge as exactly that, AngloAmerican, historically and linguistically specific ways of understanding ways of leading and people who are in positions to lead. We need to acknowledge that what we now know of ways of leading, in the form of leadership, is only a fraction of what we could, and what we should know. Our aim, therefore, is not to dismantle leadership studies, render it parochial and irrelevant. Rather, what we would like to see is a rejuvenation of the field through our proposed leadership and language multiplicity research agenda and expansion into new areas, geographically, culturally, linguistically and conceptually. 


\section{References}

Agar, M. (1994). Language Shock: Understanding the culture of conversation. New York: Morrow and Company.

Ahonen P., Tienari J., Meriläinen S. and Pullen A. (2014). Hidden contexts and invisible power relations: A Foucauldian reading of diversity management. Human Relations, 67, pp. 263-286.

Ailon, G. (2008). Mirror, mirror on the wall: Culture's Consequences in a Value-Test of its Own Design. Academy of Management Review, 33, pp. 885-904.

Ailon-Souday, G. and Kunda, G. (2003). The local selves of global workers: the social construction of national identity in the face of organizational globalization. Organization Studies, 24, pp. 1073-1096.

Altman, Y. and Laguecir, A. (2012). Leadership in the academic field of business and management and the question of origin: A commentary on Burgess and Shaw (2010). British Journal of Management, 23, pp. 589-597.

Alvesson, M. and Sveningsson, S. (2003). The great disappearing act: difficulties in doing 'leadership’. The Leadership Quarterly, 14, pp. 359-381.

Asante, M.K. and Gudykunst, W.B. (eds) (1989). Handbook of International and Intercultural Communication. Newbury Park, CA: Sage. 
Ardichvili, A. and Kuchinke, K.P. (2002). Leadership styles and cultural values among managers and subordinates: A comparative study of four countries of the former Soviet Union, Germany and US. Human Resource Development International, 5, pp. 99-117.

Bakhtin, M.M. (1996). Speech Genres and Other Late Essays. McGee VW (trans.) Austin: University of Texas Press.

Bakhtin, M.M. (2002). The Dialogical Imagination: Four Essays by M.M. Bakhtin. In Holquist M (ed) Emerson C and Holquits M. (transl.). Austin: University of Texas Press.

Bolden, R., and Kirk, P. (2009). African leadership: Surfacing new understandings through leadership development. International Journal of Cross Cultural Management, 9, pp. 69-86.

Brodbeck, F.C., Frese, M., Javidan, M. and Kroll, M.G. (2002). Leadership made in Germany: Low on compassion, high on performance. Academy of Management Executive, 16, pp. 6-30.

Brodbeck, F.C., Frese, M, Akerblom, S., Audia, G., Bakacsi, G., Bendova, Bodega, D., Bodur, M., Booth, S., Brenk, K., Castel, P., Hartog, D., Donnelly-Cox, G., Gratchev, M.V., Holmberg, I., Jarmuz, S., Jesuino, J.C., Jorbenadse, R., Kabasakel, H.E. and Keating, M. (2000). Cultural variation of leadership prototypes across 22 European countries. Journal of Occupational and Organizational Psychology, 73, pp. 1-29. 
Brummans, B.H.J.M. and Hwang, J.M. (2010). Tzu Chi's organizing for a compassionate world: insights into the communicative praxis of a Buddhist organization. Journal of International and Intercultural Communication, 3, pp. 136-163.

Bryman, A. (2004). Qualitative research on leadership: A critical but appreciative review. The Leadership Quarterly, 15, pp. 729-769.

Bryman, A. (2011). Research Methods in the Study of Leadership. In Bryman, A., Collinson, D., Grint, K., Jackson, B. and Uhl-Bien, M (eds), The SAGE Handbook of Leadership. London: Sage, pp. 15-28.

Bryman, A., Bresnen, M., Beardsworth, A. and Keil, T. (1988). Qualitative research and the study of leadership. Human Relations, 41, pp. 13-29.

Bryman, A., Stephens, M., and Campo, C. (1996). The importance of context: Qualitative research and the study of leadership. The Leadership Quarterly, 7, pp. 353-370.

Campbell, A. (2008). Leadership succession in early Islam: Exploring the nature and role of historical precedents. The Leadership Quarterly, 19, pp. 426-438.

Case, P., French, R. and P. Simpson (2011). Philosophy of Leadership. In A. Bryman, D. Collinson, K. Grint, B. Jackson and M. Uhl-Bien (eds), The Sage Handbook of Leadership. London: Sage, pp. 242-254. 
Cheng, C.-Y., Jiang, D.-Y., Cheng, B.-S., Riley, J.H. and Jen, C.-K. (2015). When do subordinates commit to their supervisors? Different effects of perceived supervisor integrity and support of Chinese and American employees. The Leadership Quarterly, 26, pp. 81-97.

Chokar, J.S., Bordbeck, F.C. and House, R.J. (eds) (2008). Culture and Leadership across the world: The GLOBE Book of In-Depth Studies of 25 Societies. New York: Taylor and Francis.

Clausen, L. (2010). Moving beyond stereotypes in managing cultural difference: Communication in Danish-Japanese corporate relationships. Scandinavian Journal of Management, 26, pp. 5766.

Clifton, J. (2015). Leaders as ventriloquists. Leader identity and influencing the communicative construction of the organisation. Leadership. Online first.

Collinson, D. (2005). Dialectics of leadership. Human Relations, 58, pp. 1419-1442.

Collinson, D. (2006). Rethinking followership: a post-structuralist analysis of follower identities. The Leadership Quarterly, 17, pp. 1419-1442.

Collinson, D. (2014). Dichotomies, dialectics and dilemmas: New directions for critical leadership studies. Leadership, 10, pp. 36-55. 
Conger, J.A. (1998). Qualitative research as the cornerstone methodology for understanding leadership, The Leadership Quarterly, 9, pp. 107-121.

Cunliffe, A.L. and Eriksen, M. (2011). Relational leadership. Human Relations, 64, pp. 14251449.

Czarniawska-Joerges, B. (1992). Exploring Complex Organizations: A Cultural Perspective.

Newbury Park: Sage.

Dansereau, F. and Yammarino, F.J. (2006). Is more discussion about levels of analysis really necessary? When is such discussion sufficient?. The Leadership Quarterly, 17, pp. 537-552.

Diaz-Saenz, H.R. (2011). Transformational Leadership. In Bryman, A., Collinson, D., Grint, K., Jackson, B. and Uhl-Bien, M. (eds), The SAGE Handbook of Leadership. London: Sage, pp. 299210.

Dickson, M. W., Resick, C. J. and Hanges, P.J. (2006). Systematic variation in organizationally shared cognitive prototypes of effective leadership based on organizational form. The Leadership Quarterly, 17, pp. 487-505.

Dorfman, P. W. (2004). International and cross-cultural leadership research. In Punnett, B. J. and Shenkar, O. (eds), Handbook for international management research. Ann Arbor, MI: University of Michigan, pp. 265-355. 
Drath, W.H., McCauley, C.D., Palus, C.J., Van Velsor, E., O’Connor, P.M.G. and McGuire, J.B. (2008). Direction, alignment, commitment: Toward a more integrative ontology of leadership. The Leadership Quarterly, 19, pp. 635-653.

Edwards, G.P., Elliott, C., Iszatt-White, M. and Schedlitzki, D. (2015). Using Creative Techniques in Leadership Learning and Development: An introduction. Advances in Developing Human Resources, 17, pp. 279-288.

Egri, C.P. and Herman, S. (2000). Leadership in the North American Environmental Sector: Values, leadership styles and the context of environmental leaders and their organisations. Academy of Management Journal, 43, pp. 571-604.

Elliott, C. and Stead, V. (2008). Learning from Leading Women's Experience: Towards a Sociological Understanding. Leadership, 4, pp. 159-180.

Elliott, C. and Stead, V. (2009). Women's Leadership. London: Palgrave Macmillan.

Fairhurst, G.T. (2007). Discursive Leadership: In conversation with leadership psychology. London: Sage. 
Fairhurst, G.T. (2011). Discursive Approaches to Leadership. In Bryman, A., Collinson, D., Grint, K., Jackson, B. and Uhl-Bien, M. (eds), The SAGE Handbook of Leadership. London: Sage, pp. 498-507.

Fairhurst, G.T. and Connaughton, S.L. (2014). Leadership: A communicative perspective. Leadership, 10, pp. 7-35.

Fairhurst, G.T. and Uhl-Bien, M. (2012). Organizational discourse analysis (ODA): Examining leadership as a relational process. The Leadership Quarterly, 23, pp. 1043-1062.

Ford, J. (2006). Discourse of Leadership: Gender, Identity and Contradiction in a Public Sector Organization. Leadership, 2, pp. 77-99.

Ford, J. (2010). Studying leadership critically: A psychosocial lens on leadership identities. Leadership, 6, pp. 47-65.

Ford, J., Harding, N. and Learmonth, M. (2008). Leadership as Identity. London: Palgrave Macmillan.

Fourie, W., van der Merwe, S. C. and van der Merwe, B. (2015). Sixty years of research on leadership in africa: A review of the literature. Leadership. Online first. 
Gaggiotti, H., Kostera, M. and Krzyworzeka, P. (2014). More than a Method? Re-founding Organizational Ethnography as a style of social imagination. 30th EGOS Colloquium:

Reimagining, Rethinking, Reshaping: Organizational Scholarship in Unsettled Times. Sub-theme 15: (SWG) Organizational Ethnography: The Theoretical Challenge. Rotterdam, The Netherlands.

Geertz, C. (1973). The interpretation of cultures. New York: Basic Books Inc.

Goetz, J.P. and LeCompte, M.D. (1984). Ethnography and qualitative design in educational research, Orlando, FL: Academic.

Gordon, R. (2002). Conceptualising leadership with respect to its historical-contextual antecedents to power. The Leadership Quarterly, 13, pp. 151-167.

Gordon, R. (2011). Leadership and Power. In Bryman, A., Collinson, D., Grint, K., Jackson, B. and Uhl-Bien, M. (eds), The Sage Handbook of Leadership. London: Sage, pp. 195-202.

Graen, G.B. (2006). In the eye of the beholder: cross-cultural lessons in leadership from project GLOBE: A response viewed from the third culture bonding (TCB) model of cross-cultural leadership. Academy of Management Perspectives, 20, pp. 95-101.

Grint, K. (2005). Problems, problems, problems: the social construction of 'leadership'. Human Relations. 58, pp. 1467-1494. 
Grint, K. (2010). Leadership: A very short introduction. Oxford: Oxford University Press.

Gudykunst, W. B. and Nishida, T. (1989). Theoretical Perspectives for Studying Intercultural Communication. In Asante, M. K. and Gudykunst, W. B. (eds), Handbook of International and Intercultural Communication. Newbury Park: Sage, pp. 17-46.

Guthey, E. and Jackson, B. (2011). Cross-cultural Leadership Revisited. In Bryman, A., Collinson, D., Grint, K., Jackson, B. and Uhl-Bien, M. (eds), The SAGE Handbook of Leadership. London: Sage, pp. 165-178.

Hamlin, R. (2005). Toward universalistic models of managerial leader effectiveness: a comparative study of recent British and American derived models of leadership. Human Resource Development International, 8, pp. 5-25.

Hanges, P.J. and Dickson, M.W. (2006). Agitation over aggregation: Clarifying the development of and nature of the GLOBE scales. The Leadership Quarterly, 17, pp. 522-536.

Hansen, H. and Bathhurst, R. (2011). Aesthetics and leadership. In Bryman, A., Collinson, D., Grint, K., Jackson, B. and Uhl-Bien, M. (eds), The SAGE Handbook of Leadership. London: Sage, pp. 255-266. 
Hofstede, G. (1980). Culture's Consequences: International Differences in Work-Related Values. Beverly-Hills: Sage Publications.

Hofstede, G. (1993). Cultures and Organizations: Software of the mind. London: McGraw-Hill.

Holiday, A., Hyde, M. and Kullman, J. (2004). Intercultural communication. Routledge.

Hosking, D.M. and Morley, I.E. (1988). The skills of leadership. In Hunt, J.G., Baliga, R., Dachler, H.P. and Schriesheim, C.A. (eds), Emerging Leadership Vistas. Lexington, MA: Lexington Press, pp. 89-106.

House, R. J., Hanges, P. J., Javidan, M., Dorfman, P.W. and Gupta, V. (Eds.) (2004). Leadership, Culture and Organizations: The GLOBE Study of 62 Societies. Sage Publications.

Islam, G. (2009). Animating leadership: Crisis and renewal of governance in 4 mythic narratives. The Leadership Quarterly, 20, pp. 828-836.

Jack, G., Westwood, R., Srinivas, N., and Sardar, Z. (2011). Deepening, broadening and reasserting a postcolonial interrogative space in organization studies. Organization, 18, 275-302.

Jepson, D. (2009). Studying leadership at cross-country level: A critical analysis. Leadership, 5, pp. 1-80. 
Jepson, D. (2010). The importance of national language as a level of discourse within individuals' theorising of leadership - a qualitative study on German and English employees. Leadership, 6, pp. 425-445.

Julien, M., Wright, B. and Zinni. D.M. (2010). Stories from the circle: Leadership lessons learned from aboriginal leaders. Leadership Quarterly, 21, pp. 114-126.

Jung, D.I. and Avolio, B.J. (1999). Effects of leadership styles and followers' cultural orientation on performance in group and individual task conditions. Academy of Management Journal, 42, pp. 208-218.

Jung, D., Yammarino, F. J. and Lee, J.K. (2009). Moderating role of subordinates' attitudes on transformational leadership and effectiveness: a multi-cultural and multi-level perspective. The Leadership Quarterly, 20, pp. 586-603.

Kakabadse, A.K., Kakabadse, N.K. and Myers, A. (1996). Leadership and the public sector: An internationally comparative benchmarking analysis. Public Administration and Development, 16, pp. 377-396.

Kempster, S., and Stewart, J. (2010). Becoming a leader: A co-produced autoethnographic exploration of situated learning of leadership practice. Management Learning, 41, pp. 205-219. 
Koivunen, N. (2007). The processual nature of leadership discourses. Scandinavian Journal of Management, 23, pp. 285-305.

Koselleck, R. (2002). The practice of conceptual history: timing history, spacing concepts. Stanford: Stanford University Press.

Ladkin, D. (2006). The enchantment of the charismatic leader: charisma reconsidered as aesthetic encounter. Leadership, 2, pp. 165-179.

Ladkin, D. (2008). Leading beautifully: How mastery, congruence and purpose create the aesthetic of embodied leadership practice. The Leadership Quarterly, 19, pp. 31-41.

Lee, K., Scandura, T.A. and Sharif, M.M. (2014). Cultures have consequences: A configural approach to leadership across two cultures. The Leadership Quarterly, 25, pp. 692-710.

Lin, C. and Clair, R.P. (2007). Measuring Mao Zedong thought and interpreting organizational communication in China. Management Communication Quarterly, 20, pp. 395-429.

Lucy, J. (2000). Introductory comments. In Niemeier, S. and Dirven. R. (eds), Evidence for Linguistic Relativity. Amsterdam, PA: John Benjamins Publisher, pp. ix-xxi.

Maitlis, S. and Lawrence, T.B. (2007). Triggers and enablers of sensegiving in organizations. Academy of Management Journal, 50, pp. 57-84. 
Martin, G.S., Keating, M.A., Resick, C.J., Szabo, E., Kwan, H.K. and Peng, C. (2013). The meaning of leader integrity: A comparative study across Anglo, Asian and Germanic cultures. The Leadership Quarterly, 24, pp. 445-461.

McCarthy, G. (2005). Leadership practices in German and UK organisations. Journal of European Industrial Training, 29, pp. 217-234.

McSweeney, B. (2002). Hofstede's model of national cultural differences and their consequences: a triumph of faith - a failure of analysis. Human Relations, 55, pp. 89-118.

Meriläinen, S., Tienari, J., Thomas, R. and Davies, A. (2008). Hegemonic academic practices: Experiences of publishing from the periphery. Organization, 15, pp. 584-597.

Meyer R. E. and Boxenbaum E. (2010). Exploring European-ness in Organization Research. Organization Studies, 31, pp. 737-55.

Mueller, M. (2007). What's in a Word? Problematizing Translation between Languages. Area, 39, pp. 206-213.

Muhr, S.L. and Sullivan, K.R. (2013). "None so queer as folk": Gendered Expectations and Transgressive Bodies in Leadership. Leadership, 9, pp. 416-435. 
Neal, M.W. and Tansey, R. (2010). The dynamics of effective corrupt leadership: Lessons from Rafik Hariri's political career in Lebanon. The Leadership Quarterly, 21, pp. 33-49.

Nkomo, S. M. (2011). A postcolonial and anti-colonial reading of 'African' leadership and management in organization studies: Tensions, contradictions and possibilities. Organization, 18, pp. 365-386.

Ooi, C.-S. (2007). Unpacking packaged cultures: Chinese-ness in international Business. East Asia, 24, pp. 11-128.

Osborn. R.N. and Marion, R. (2009). Contextual leadership, transformational leadership and the performance of international innovation seeking alliances. The Leadership Quarterly, 20, pp. 191-206.

Parry, K., Mumford, M.D., Bower, I. and Watts, L.I. (2014). Qualitative and historiometric methods in leadership research: A review of the first 25 years of The Leadership Quarterly. The Leadership Quarterly, 25, pp. 132-151.

Peltonen, T. (2012). Kohti johtamisen käsitehistoriaa Suomessa: 1950-luvun oppikirjojen kieli. Hallinnon Tutkimus, 31, pp. 277-293. 
Peterson, M. F. and Castro, S.L. (2006). Measurement metrics at aggregate levels of analysis: Implications for organization culture research and the GLOBE project. The Leadership Quarterly, 17, pp. 506-521.

Prince, L. (2006). Eating the Menu rather than the Dinner: Tao and Leadership. Leadership, 1, pp. 105-126.

Pye, A. (2005). Leadership and organizing: Sense-making in action. Leadership, 1, pp. 31-50.

Redpath, L. and Nielsen, M. (1997). A comparison of native culture, non-native culture and new management. Canadian Journal of Administrative Science, 14, pp. 327-339.

Reynolds, M. (1999). Grasping the Nettle: Possibilities and Pitfalls of a Critical Management Pedagogy. British Journal of Management, 19, pp. 171-184.

Riad, S. (2011). Invoking Cleopatra to examine the shifting ground of leadership. The Leadership Quarterly, 22, pp. 831-850.

Ropo, A., Parviainen, J. and Koivunen, N. (2002). Aesthetics in leadership: From absent bodies to social bodily presence. In Parry, K.W. and Meindl, J.R. (eds), Grounding Leadership Theory and Research: Issues, Perspectives and Methods. Greenwich, CT: Information Age Publishing, pp. 21-38. 
Rowlinson, M. and Hassard, J. (2013). History and the cultural turn in organization studies. In Bucheli, M. and Wadhwani, R.D. Organizations in Time: History, Theory, Methods. Oxford: Oxford University Press, pp. 147-165.

Sadri, G., Weber, T.J. and Gentry, W.A. (2011). Emphatic emotion and leadership performance: An empirical analysis across 38 countries. The Leadership Quarterly, 22, pp. 818-830.

Scandura, T. and Dorfman, P. (2004). Leadership research in an international and cross-cultural context. The Leadership Quarterly, 15, pp. 277-307.

Schaubroeck, J., Lam, S.S.K. and Cha, S.E. (2007). Embracing transformational leadership: team values and the impact of leader behavior on team performance. Journal of Applied Psychology, 92, pp. 1020-1030.

Schedlitzki, D., Edwards, G. and While, G. (2013). Leadership and the Welsh Language, Paper presented at EGOS conference in Montreal, Canada.

Schedlitzki, D., Jarvis, C. and MacInnes, J. (2015). Leadership Development: A place for storytelling and Greek Mythology?. Management Learning, 46, pp. 412-426.

Schneider, J. and Littrell, R.F. (2003). Leadership preferences of German and English managers. Journal of Management Development, 22, pp. 130-148. 
Schyns, B., Tymon, A., Kiefer, T. and Kerschreiter, R. (2013). New ways of leadership development: A picture paints a thousand words. Management Learning, 44, pp. 11-24.

Slobin, D.I. (2000). Verbalized events: A dynamic approach to linguistic relativity and determinism. In Niemeier, S. and Dirven. R. (eds), Evidence for Linguistic Relativity. Amsterdam, PA: John Benjamins Publisher, pp. 107-138.

Snell-Hornby M. (2010). Is Translation Studies Going Anglo-Saxon? Critical Comments on the Globalization of a Discipline. In Gile, D., Hansen, G. and Pokorn, N.K. (eds), Why Translation Studies Matters. Amsterdam: John Benjamins, pp. 97-104.

Spreitzer, G.M., Perttula, K.H. and Xin, K. (2005). Traditionality matters: an examination of the effectiveness of transformational leadership in the United States and Taiwan. Journal of Organizational Behavior, 26, pp. 205-227.

Srinivas, N. (2013). Could a subaltern manage? Identity work and habitus in a colonial workplace. Organization Studies, 34, pp. 1655-1674.

Stephens, J. (2003). The rhetoric of women's leadership: Language, memory and imagination. Journal of Leadership and Organizational Studies, 9, pp. 45-60.

Steyaert, C. and Janssens, M. (2013). Multilingual scholarship and the paradox of translation and language in management and organization studies. Organization, 20, pp. 131-142. 
Sutherland, I. (2013). Arts-based methods in leadership development: Affording aesthetic workplaces, reflexivity and memories with momentum. Management Learning, 44, pp. 25-44.

Sutherland, N., Bohm, S. and Land, C. (2013). Anti-leaders(hip) in social movement organisations: The case of autonomous grassroots groups. Organization. Online first.

Suutari, V. (1996). Variation in average leadership behaviour of managers across countries:

Finnish expatriates' experiences from Germany, Sweden, France and Great Britain. International Journal of Human Resources Management, 7, pp. 677-707.

Suutari, V. (1998). Leadership behaviour in Eastern Europe: Finnish expatriates' experience in Russia and Estonia. International Journal of Human Resources Management, 9, pp. 235-258.

Sveiby, K. (2011). Collective leadership with power symmetry: Lessons from Aboriginal prehistory. Leadership, 7, pp. 385-414.

Tayeb, M. (2001). Conducting Research Across Cultures: overcoming drawbacks and obstacles. International Journal of Cross Cultural Management, 1, pp. 91-108.

Taylor, S. and Ladkin, D. (2009). Understanding arts-based methods in managerial development. Academy of Management Learning and Education, 8, pp. 55-69. 
Tietze, S. Cohen, L. and Musson, G. (2003). Understanding organizations through language. London: Sage.

Tourish, D. (2014). Leadership more or less? A processual, communication perspective on the role of agency in leadership theory. Leadership, 10, pp. 79-98.

Turnbull, S. (2009). Worldly leadership for a global world. In Harvey, M. and Barbour, J.D. (eds), Global Leadership: Portraits of the Past, Visions of the Future. College Park, MD: ILA, pp. 82-94.

Turnbull, S., Case, P., Edwards, G., Jepson, D. and Simpson, P. (2012). Worldly Leadership. London: Palgrave.

Uhl-Bien, M. and Ospina, S. (eds) (2012). Advancing relational leadership research: A dialogue among perspectives. Charlotte, NC: Information Age.

Vaara, E., and Lamberg, J.-A. (2015). Taking historical embeddedness seriously: Three historical approaches to advance strategy process and practice research. Academy of Management Review. Online first.

Venuti L. (1998). The Scandals of Translation: Towards an Ethics of Difference. London: Routledge. 
Warner, L.S., and Grint, K. (2006). American Indian ways of leading and knowing. Leadership, 2, pp. 225-244.

Wasti, S. A., Tan, H. H., Brower, H. H. and Onder, C. (2007). Cross-cultural measurement of supervisor trustworthiness: An assessment of measurement invariance across three cultures. The Leadership Quarterly, 18, pp. 477-489.

Weatherbee, T. G. (2012). Caution! This historiography makes wide turns: Historic turns and breaks in management and organization studies. Management and Organizational History, 7, pp. 203-218.

Welch, C. and Piekkari, R. (2006). Crossing Language Boundaries: Qualitative Interviewing in International Business. Management International Review, 46, pp. 417-37.

Wendt, H., Euwema, M.C. and Hetty van Emmerik, I.J. (2009). Leadership and team cohesiveness across cultures. The Leadership Quarterly, 20, pp. 258-370.

Xu, K. (2011). An empirical study of Confucianism: measuring Chinese academic leadership. Management Communication Quarterly, 25, pp. 644-662.

Yang, S. Y. (2011). Wisdom displayed through leadership: Exploring leadership-related wisdom, The Leadership Quarterly, 22, pp. 616-632. 
Zander, L., Mockaitis, A.L. and Harzing, A.-W. (2011). Standardization and contextualisation: A

Study of language and leadership across 17 countries. Journal of World Business, 46, pp. 296304.

Zhang, X., Fu, P., Xi, Y., Li, L., Xu, L., Cao, C., Li, G., Ma, L. and Ge, J. (2012). Understanding indigenous leadership research: Explication and Chinese examples. The Leadership Quarterly, 23, pp. 1063-1079.

Zoller, H.M. and Fairhurst, G.T. (2007). Resistance Leadership: The overlooked potential in critical organizations and leadership studies. Human Relations, 60, pp. 1331-1360.

\section{Tables and figures}

Table 1: Examples of methodological approaches within the leadership and language multiplicity research agenda

\begin{tabular}{|l|l|l|l|}
\hline Method/approach & $\begin{array}{l}\text { Level of } \\
\text { analysis }\end{array}$ & Examples & Useful References \\
\hline $\begin{array}{l}\text { Language use } \\
\text { analyses and } \\
\text { conceptual histories }\end{array}$ & Macro & $\begin{array}{l}\text { Exploration of culturally } \\
\text { and/or language-specific } \\
\text { conceptual histories of } \\
\text { leadership concepts. }\end{array}$ & $\begin{array}{l}\text { Koivunen 2007; Jepson } \\
\text { 2009; Peltonen 2012 }\end{array}$ \\
\hline $\begin{array}{l}\text { Creative and } \\
\text { projective } \\
\text { techniques }\end{array}$ & Macro & $\begin{array}{l}\text { Use of word cards and } \\
\text { cultural artefacts to } \\
\text { encourage an open, } \\
\text { interactive discussion of } \\
\text { leadership concepts and } \\
\text { ways of leading; repeatable } \\
\text { for longitudinal study. }\end{array}$ & $\begin{array}{l}\text { Stephens 2003; } \\
\text { Schedlitzki et al. 2013 }\end{array}$ \\
\hline Auto-ethnographies & Macro & $\begin{array}{l}\text { Reflective diaries to } \\
\text { capture participants' } \\
\text { episodic reflections on their } \\
\text { personal meaning-making }\end{array}$ & Kempster and Stewart \\
\hline
\end{tabular}




\begin{tabular}{|c|c|c|c|}
\hline & & processes on leadership. & \\
\hline $\begin{array}{l}\text { Organisational } \\
\text { ethnographies }\end{array}$ & Micro & $\begin{array}{l}\text { Through observations, } \\
\text { conversations, reflective } \\
\text { diaries etc., gain an } \\
\text { understanding of particular } \\
\text { local uses and } \\
\text { interpretations of words, } \\
\text { forms (in particular, } \\
\text { metaphors) and meanings } \\
\text { and sense-making and } \\
\text { sense-giving processes. } \\
\text { Exploration of the fluid and } \\
\text { changing nature of } \\
\text { individuals' or groups' } \\
\text { understanding and practice } \\
\text { of leadership. }\end{array}$ & $\begin{array}{l}\text { Maitlis and Lawrence } \\
2007\end{array}$ \\
\hline $\begin{array}{l}\text { Aesthetically } \\
\text { informed, visual or } \\
\text { arts-based } \\
\text { techniques }\end{array}$ & Micro & $\begin{array}{l}\text { Use of aesthetically } \\
\text { informed, visual or arts- } \\
\text { based techniques such as } \\
\text { drawing to encourage } \\
\text { reflection on specific, local } \\
\text { meaning-making processes, } \\
\text { adding to our cultural } \\
\text { understanding of leadership } \\
\text { as an embodied practice. }\end{array}$ & $\begin{array}{l}\text { Ropo et al. 2002; Taylor } \\
\text { and Ladkin 2009; Hansen } \\
\text { and Bathurst 2011; Schyns } \\
\text { et al. } 2013\end{array}$ \\
\hline Auto-ethnographies & Micro & $\begin{array}{l}\text { Reflective diaries to } \\
\text { capture participants' } \\
\text { episodic reflections on } \\
\text { local practices and ways of } \\
\text { using language or forming } \\
\text { sub- or organisational } \\
\text { cultural meanings. }\end{array}$ & $\begin{array}{l}\text { Kempster and Stewart } \\
2010\end{array}$ \\
\hline $\begin{array}{l}\text { Dialogical and } \\
\text { discursive analyses }\end{array}$ & $\begin{array}{l}\text { Macro and } \\
\text { Micro }\end{array}$ & $\begin{array}{l}\text { Exploring multiplicity of } \\
\text { specific conceptual } \\
\text { meanings and highlight } \\
\text { political and gendered, } \\
\text { racialized and other power } \\
\text { relations at play in } \\
\text { language use within and } \\
\text { across specific local, socio- } \\
\text { historic cultural contexts } \\
\text { and research teams. }\end{array}$ & $\begin{array}{l}\text { Venuti 1998; Alvesson } \\
\text { and Sveningsson 2003; } \\
\text { Welch and Piekkari 2006; } \\
\text { Mueller 2007; Fairhurst } \\
\text { 2011; Fairhurst and Uhl- } \\
\text { Bien } 2012\end{array}$ \\
\hline
\end{tabular}

